\title{
Robotic resection of retrorectal tumor: an alternative to the Kraske procedure
}

\author{
Stergiani Agorastos, Asha Alex, Joshua Feldman, Michael Kuncewitch, Gary Deutsch, Eric \\ Siskind, J effrey Nicastro, Gene F. Coppa, Charles Conte, Mansoor Beg, Alan Kadison, \\ John Ricci, J ohn Hsiang-Yeou Wang, Raza Zaidi, Lynn O'Connor, Michael Nimaroff, \\ Ernesto P. Molmenti, James D. Sullivan \\ Departments of Surgery and Surgical Oncology, Hofstra North Shore-LIJ School of Medicine, Manhasset, NY, USA
}

Correspondence: Michael Kuncewitch. Address: Department of Surgery, Hofstra North-Shore LIJ School of Medicine 300 Community Drive, Manhasset, NY 11030, USA. E-mail: mkuncewtic@nshs.edu

Received: May 8, 2013

DOI : $10.5430 /$ jst.v3n4p13
Accepted: May 23, 2013

URL: http://dx.doi.org/10.5430/jst.v3n4p13

Online Published: July 12, 2013

\section{Abstract}

The Kraske procedure is a surgical technique in which the presacral space is accessed by removal of the coccyx and portions of the sacrum. This is an accepted procedure for mid-rectal lesions. An alternative to the Kraske procedure is Robotic-assisted Laparoscopy (RAL), a minimally invasive alternative approach that offers numerous benefits. We present the case of a patient with a retrorectal duplication cyst resected using a robotic-assisted laparoscopic procedure.

\section{Key words}

Robotic, Laparoscopy, Kraske, Presacral mass, Duplication cyst

\section{I ntroduction}

The Kraske procedure (originally developed by Paul Kraske in 1884 for carcinoma of the rectum) allows access to the rectum via the presacral space in instances where the lesion cannot be addressed transanally ${ }^{[1]}$. The most common presacral masses are developmental cysts ${ }^{[2-4]}$, which histologically can be classified as epidermoid, dermoid, and enteric cysts. The latter can be subdivided into mucus-secreting and duplication cysts ${ }^{[3,5]}$.

Middle-aged females are more likely to have developmental cysts, with a 3:1 ratio when compared to their male counterparts. Although, it is estimated that about half of patients are asymptomatic, symptoms at presentation are usually associated with size (mass effect) and the presence of infections ${ }^{[3]}$.

Differential diagnoses include cystic sacrococcygeal teratoma, perirectal abscess, presacral abscess, pilonidal disease, fistula in ano, anterior sacral meningocele, anal duct or gland cyst, necrotic rectal leiomyosarcoma, extraperitoneal adenomucinosis, cystic lymphangioma, pyogenic abscess, neurogenic cyst, and necrotic sacral chordoma ${ }^{[3,5]}$. Complete excision is both diagnostic and therapeutic for developmental cysts ${ }^{[3]}$. 
Although the Kraske procedure has been traditionally useful for the removal of presacral lesions, more minimally invasive procedures associated with improved patient satisfaction are currently available. This study describes the surgical resection of a rectorectal duplication cyst using robotic-assisted laparoscopy.

\section{Case report}

A 47-year old female presented with a 2-month history of vague, worsening discomfort in the rectal region attributed to repeated urinary tract infections. The patient noticed the pain was associated with bowel movements, and was occasionally accompanied by rectal bleeding, itching and burning. She denied weight loss, prolapse, diarrhea, mucous drainage, or discharge. Past medical history included surgical treatment of a ruptured ovarian cyst at age 24 . Her last colonoscopy was 3 years prior to presentation. No alcohol abuse or smoking was reported.

CT imaging at an outside institution showed a questionable perirectal abscess approximately $4 \mathrm{~cm}$ in size present in the inferior most aspect of the pelvis, immediately anterior to the distal sacrum and coccyx (see Figure 1). It had an enhancing, irregular wall, with a maximum diameter of approximately $5 \mathrm{~mm}$ and was thought to be the cause of the displacement of the rectum anteriorly and to the left.

a

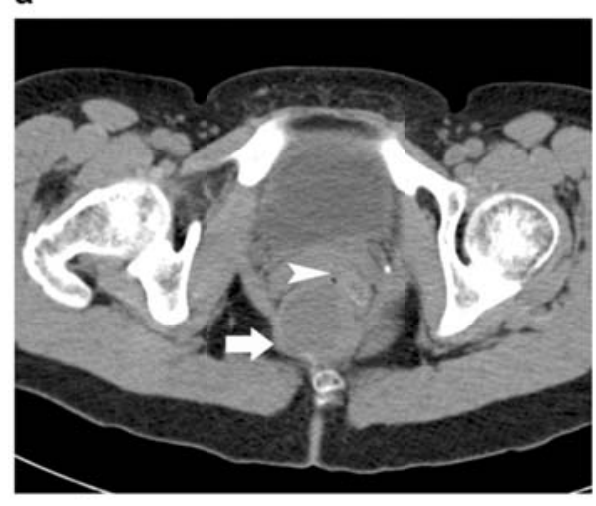

b

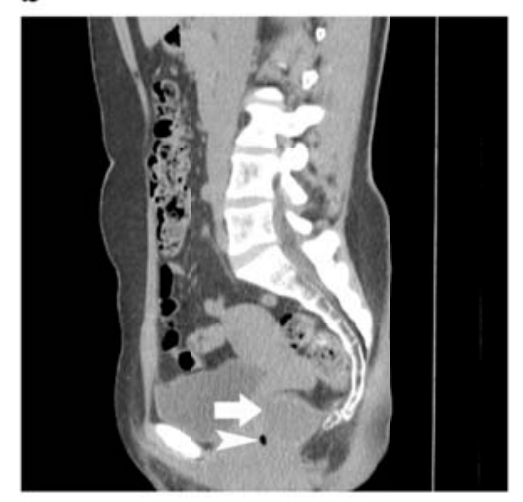

c

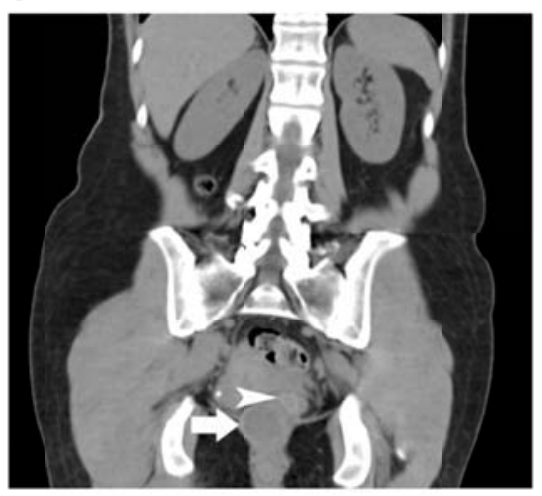

Figure 1. Computed tomography imaging of the pelvis of a 47 year old woman demonstrating a retrorectal mass (arrows) causing anterior displacement of the rectum (arrowheads) shown in the axial (a), sagittal (b), and coronal (c) planes.

For the next two years, numerous consultations took place. Given her constellation of symptoms, a colonoscopic evaluation was recommended, which revealed a $4-5 \mathrm{~cm}$ soft tissue pre-sacral mass in the rectum. For further evaluation of the mass, an MRI with contrast was performed one month later, which showed a $3.3 \mathrm{~cm} \times 3.8 \mathrm{~cm} \times 3.0 \mathrm{~cm}$ lobular cyst arising from the right posterior wall of the mid to lower rectum without any evident communication with the lumen (Figure 2). The cyst was stable in size, and likely represented a congenital rectal duplication cyst. It did not have soft tissue components, but showed thickened lobulations, an enhancing wall, and septations, suggesting a complex nature. A small $1.5 \mathrm{~cm} \times 1.0 \mathrm{~cm} \times 1.2 \mathrm{~cm}$ bilobed perirectal fatty nodule between the rectosigmoid junction and vaginal roof consisting of a dominant posterior fatty component and a small enhanced anterior nonfatty component, not previously seen on CT, were also found.

Three months after the MRI, the patient underwent a second colonoscopy and endoscopic ultrasound (EUS), with findings consistent with a $35 \mathrm{~mm} \times 26 \mathrm{~mm}$ perirectal duplication cyst. This was not sampled by EUS-FNA due to the EUS appearance of a cyst with layered architecture. Complete surgical excision was recommended and the patient underwent robotic-assisted laparoscopic resection of a retrorectal cyst. 
a

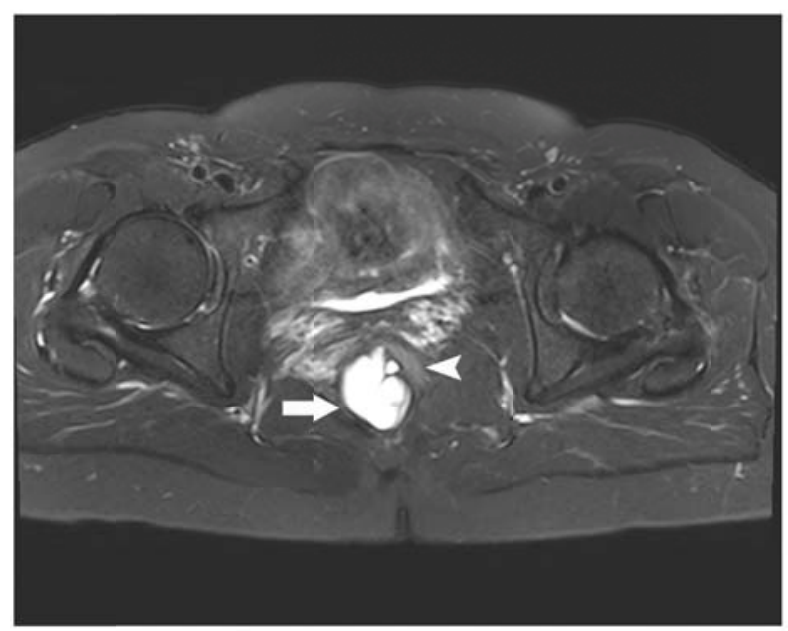

b

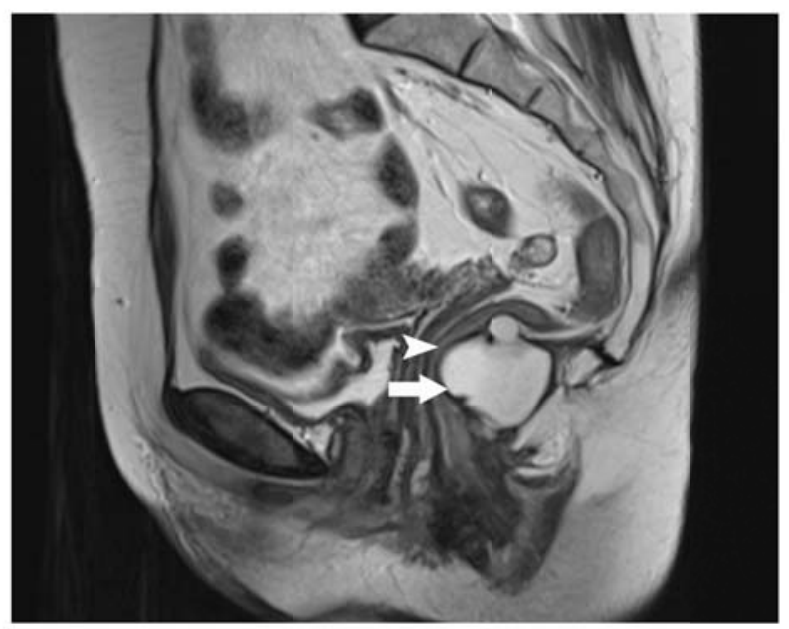

Figure 2. Magnetic resonance imaging of the pelvis of a 47 year old woman demonstrating a retrorectal mass (arrows) causing anterior displacement of the rectum (arrowheads) shown in the axial (a) and sagittal (b) planes.

In the operating room the patient was placed in a modified Lloyd-Davies position in Allen stirrups. Digital rectal exam revealed the mass to be in a very distal retrorectal area just above the levator in the posterior midline slightly to the right. A robot camera port was placed through a 10-mm $20 \mathrm{~mL}$ balloon-applied Medical Hasson. Additional trocars were placed in the left lateral abdomen, left mid abdomen, right mid abdomen, right lateral abdomen and right mid abdomen. Robotic mobilization of the rectum was accomplished by incising the lateral peritoneal attachments and dissecting the retrorectum and the posterior midline. The cyst was ultimately dissected free of the retrorectal area, and a 60/3.5 stapler used to divide the mesorectum between rectum and cyst. The procedure was completed in 3 hours and 50 minutes. The patient tolerated the procedure well and was transported to the recovery room in stable condition. She went home the following day.

Pathology exam revealed an epidermal inclusion cyst with focal acute inflammation and foreign body giant cell reaction. The patient was seen again 3 months after the initial procedure and did not have any complications.

\section{Discussion}

Robotic-assisted laparoscopy is a relatively new, minimally invasive technique. A recent case-matched study showed significant differences in postoperative recovery outcomes between robotic surgery and laparoscopic surgery in patients with rectal cancer ${ }^{[6]}$. Benefits included diminished blood loss, shorter recovery times, shorter time to resume a soft diet, and shorter hospital stays ${ }^{[6]}$. Other advantages of robotic surgery include less post-operative pain, decreased narcotic use, scar reduction, and less staff required to complete the procedure ${ }^{[6,7]}$. In addition, one recent review of patients undergoing the Kraske procedure at a major academic center reported a rectal fistulization rate of $17 \%$ and a $9 \%$ rate of wound infections requiring intravenous antibiotics, which leads us to speculate that a robotic approach my contribute to a decrease in wound infections ${ }^{[8]}$. Ultimately, the greatest advantage of a robotic approach to the presacral space may be retraction and dexterity provided by the instruments in this confined space, thereby improving surgical technique. Potential disadvantages of the robotic technology include longer operative times, the high cost of the robotic platform, disposable instruments, and annual service contracts ${ }^{[6,7]}$.

It is important to consider specific characteristics of the lesion such as origin, size, precise location, communication with nearby structures, when evaluating the use of robotic surgery in any given situation. In this case, there was no communication of the cyst with the lumen of the rectal wall, which aided in the justification for use of this technique. 
Choosing to use a robotic-assisted-laparoscopic approach should be determined on a case-by-case basis, with thorough assessment of its risks and benefits. With constant advances being made in technology, the future of robotic assisted procedures is undergoing a promising evolution. Further research and clinical studies must be done to explore its advantages.

\section{References}

[1] Lorentziadis M, et al., Kraske’s posterior approach to the mid rectum; does it still have a place in the surgeon's armentarium. Annals of Gastroenterology. 2010; 23(3): 302-306. PMid:22655127 http://dx.doi.org/10.4240/wjgs.v4.i5.126

[2] Aranda-Narvaez JM, et al. Posterior approach (Kraske procedure) for surgical treatment of presacral tumors. World journal of gastrointestinal surgery. 2012; 4(5): 126-30. PMid:11353107

[3] Dahan H, et al., Retrorectal developmental cysts in adults: Clinical and radiologic-histopathologic review, differential diagnosis, and treatment. Radiographics. 2001; 21(3): 575-584. PMid:19057717

[4] Jarboui S, et al., Retrorectal cystic hamartoma associated with malignant disease. Canadian Journal of Surgery. 2008; 51(6): E115-E116. PMid:19057717

[5] Singer MA, et al., Retrorectal cyst: A rare tumor frequently misdiagnosed. Journal of the American College of Surgeons. 2003; 196(6): 880-886. http://dx.doi.org/10.1016/S1072-7515(03)00133-9

[6] Kang J, et al. The Impact of Robotic Surgery for Mid and Low Rectal Cancer A Case-Matched Analysis of a 3-Arm Comparison-Open, Laparoscopic, and Robotic Surgery. Annals of Surgery. 2013; 257(1): 95-101. PMid:23059496 http://dx.doi.org/10.1097/SLA.0b013e3182686bbd

[7] Leddy L, et al. Robotic Surgery: applications and cost effectiveness. Open Access Surgery. 2010; 3(1): 99-107. http://dx.doi.org/10.2147/OAS.S10422

[8] Onaitis M, et al. The Kraske Procedure: A Critical Analysis of a Surgical Approach For Mid-Rectal Lesions. Journal of Surgical Oncology. 2006; 94: 194-202. PMid:16900535 http://dx.doi.org/10.1002/jso.20591 